\title{
6248
}

BNWL-2062

UC-11

\section{Workshop Summary}

Regional Studies Program

Workshop on Air Quality

and Meteorological

Assessments

by

David S. Renne

June 1976

Prepared for the Energy Research and Development Administration under Contract E(45-1):1830 


\section{NOTICE}

This report was prepared as an account of work sponsored by the United States Covernment. Neither the United States nor the Energy Research and Development Administration, nor any of their employees, nor any of their contractors, subcontractors, or their employees, makes any warranty, express or implied, or assumes any legal liability or responsibility for the accuracy, completeness or usefulness of any imformation, apparatus, product or process disclosed, or represents that its use would not infringe privately owned rights.

PACIFIC NORTHWEST LABORATORY

operated by

BATTELLE

for the

ENERGY RESEARCH AND DEVELOPMENT ADMINISTRATION

Under Contract E(45-1)-1830

Price: Printed Copy \$5.00; Microfiche $\$ 2.25$ 
BNWL-2062

$\mathrm{UC}-11$

WORKSHOP SUMMARY

REGIONAL STUDIES PROGRAM WORKSHOP ON

AIR QUALITY AND METEOROLOGICAL ASSESSMENTS

by

David S. Renne

Atmospheric Sciences Department

June 1976

Battelle

Pacific Northwest Laboratories

Richland, Washington 99352 
A Regional Studies Program Workshop on Air Quality and Meteorological Assessments was held at the BattelleNorthwest Auditorium on March 9-10, 1976. Approximately twenty-three participants, including representatives from Battelle, Pacific Northwest Laboratory, Lawrence Livermore Laboratory, Los AZamos Scientific Laboratory, Argonne National Laboratory, Oak Ridge National Laboratory, Brookhaven National Laboratory, the Energy Research and Development Administration and a Washington State publicly owned utility, exchanged technical and philosophical views on their approach to performing assessments under the Regional Studies Program. Discussions included the technical approach underway at each Zaboratory, assessment objectives and techniques, and data needs and availability. 


\section{CONTENTS}

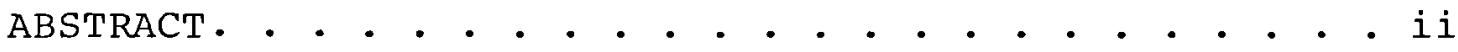

1. INTRODUCTION. • • • . . . . . . . . . . . . . . 1

2. INDIVIDUAL LABORATORY PROGRAMS. • . . . . . . . . . 4

3. ASSESSMENT OBJECTIVES • . . . . . . . . . . . 13

4. ASSESSMENT TECHNIQUES • . • . • . • • . • • . . 15

5. DATA NEEDS AND AVAILABILITY . . . . . . . . . . 19

6. SUMMARY . . . . . . . . . . . . . . . . . 21

ACKNOWLEDGMENTS . . . . . . . . . . . . . . . 24

REFERENCES. •. . . . . . . . . . . . . . . 25 


\section{INTRODUCTION}

The Regional Studies Program Workshop on Air Quality and Meteorological Assessments was held at the BattelleNorthwest auditorium on March 9-10, 1976 in Richland, washington. The workshop represented the first opportunity for meteorologists and other scientists among the various national laboratories who are concerned with assessing the air quality impacts of future energy development scenarios to assemble in one place for the express purpose of presenting their programs, airing their technical and philosphical views, and discussing their individual and collective future plans. The Regional studies Program (RSP), sponsored under the auspices of the Analysis and Assessment Branch of the Division of Biomedical and Environmental Research (DBER) of the Energy Research and Development Administration (ERDA), was initiated roughly a year and half ago among six national laboratories with the goal of assessing the socieconomic and environmental impacts of alternative energy development scenarios throughout different regions of the country. Representatives of each of the six laboratories (Battelle, Lawrence Livermore, Los Alamos, Argonne, Oak Ridge, and Brookhaven) as well as ERDA and a Washington state publicly-owned utility participated in the workshop (Table I). 
TABIJE 1. Workshop Participants

D. Renne

C. Elderkin

W. Swift

J. Fox

D. Elliott

I. Wendell

W. Davis

D. Powell

J. Droppo

R. Hill

D. Ermak

G. Hinman

E. Leonard

B. Clements

L. Habegger

K. Brubaker

C. Sheih

B. Murphy

W. Emanuel

R. Meyers

R. Cederwall

J. Zillich

R. Woodruff
Battelle, Pacific Northwest Laboratory

\begin{tabular}{|c|c|c|c|}
\hline " & " & " & " \\
\hline " & " & " & " \\
\hline " & " & $"$ & " \\
\hline " & " & " & " \\
\hline " & " & " & " \\
\hline " & " & " & " \\
\hline " & " & " & " \\
\hline " & " & " & " \\
\hline " & " & " & " \\
\hline
\end{tabular}

Lawrence Livermore Laboratory

Los Alamos Scientific Laboratory

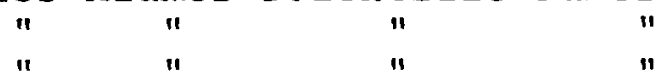

Argonne National Laboratory

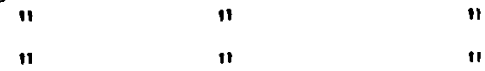

Oak Ridge National Laboratory

Brookhaven National Laboratory

Energy Research \& Development

Administration (Richland)

Washington Public Power Supply system 
Although differences exist among the objectives and approach of each laboratory in this multidisciplinary program, all of the individual programs have brought together scientific and technical expertise from a number of different disciplines to concentrate on the numerous problems each particular region faces in meeting energy-related supply and demand options. Inherent in all these programs is the study and assessment of present and future air quality impacts, including their health, agricultural and ecological implications. Thus the Regional studies Program is an important effort of national significance where the atmospheric scientist can both contribute to and benefit from the many other disciplines which orient technical competence and expertise toward a common goal.

This report attempts to describe, strictly through the author's own and hopefully somewhat objective interpretations, how meteorologists and other scientists from each of the laboratories perceive their role in this Regional studies Program, how they are implementing these studies, and how the workshop participants as a group view the overall objectives of the RSP, the assessment techniques available or required, the data needs and availability, and the interlaboratory cooperation necessary to meet these objectives. Although this report represents the work of one author, it is intended to reflect to a large degree the feeling and understandings 
represented by all the workshop participants, each of whom has had an opportunity to incorporate his comments into this discussion.

\section{INDIVIDUAL LABORATORY PROGRAMS}

A representative of each laboratory gave an informal presentation on the direction he has taken in performing regional energy-related air quality assessments within his group's RSP. These presentations represented a major catalyst for all the discussions that followed during the remainder of the workshop, and also indicated the diversity as well as the commonality that can exist in the various approaches taken by different laboratories within a broadly-scoped program.

The program at Battelle, Pacific Northwest Laboratories (PNL) has taken the approach of simulating the energy system of the Pacific Northwest (Alaska, Washington, Oregon, Idaho, Montana, Wyoming). This region finds itself in a position of being a major energy exporter, given the large coal reserves in Alaska, Montana, and Wyoming, oil in Alaska, nuclear and hydroelectric developments, and imports of Canadian oil and natural gas. Nevertheless the region must bear the brunt of the socioeconomic and environmental impacts caused by the development of these resources. These impacts are compounded by rapid population growth and associated energy demand increases in certain locales within the region. At the same 
time it faces possible nuclear and hydroelectric development moratoriums and Canadian energy import cut-offs. Thus the conflicts between energy development and environmental protection are heightened in this region characterized by a low population density and numerous scenic parks, monuments, and forests - a popular vacationland for millions of urban dwellers from other parts of the country. To examine the air quality impacts of future energy development options within the region, Dennis Elliott described PNL's first-year approach of applying a regional scale transport, transformation and removal model to existing and proposed energy-related facilities utilizing low sulfur western coal in the Northwest. This model provides information on the sulfur dioxide and sulfate budget of the region, including surface air concentrations and wet and dry deposition on the terrestrial environment. In the Northwest as well as in virtually every other part of the country the potential for conflicts between energy and agricultural production become greater and greater as fossilfueled electrical generation facilities, coal gasification and liquefaction processes, and petroleum refineries are located in the more rural and remote areas. In addition, large emissions of sulfur are now known to be transported great distances before being removed from the atmosphere and deposited onto the terrestrial environment through wet and dry processes, requiring the use of the more complex regional scale transport models. The model being applied at PNL 
interpolates the low level winds from rawinsonde and pibal observations in both time and space to a uniform grid. This wind field is then used to compute the transport of a series of massless particles, which correspond to an emission source, at any location within the grid. Vertical diffusion is Gaussian, and horizontal diffusion is determined from the meandering of the wind field. The effect of topography on the transport, diffusion and deposition of pollutants is being included in the model. Most of the energy resources of the west are located in regions of complex terrain, and it is important that topographic effects are incorporated in the assessment methods.

The Lawrence Livermore Laboratory is conducting a long-term program called the Imperial Valley Environmental Project (IVEP). The Imperial Valley of California is an area of known geothermal resources and efforts are presently underway to exploit these resources. In addition to its geothermal resources, the Imperial Valley contains an extensive agricultural system which produced a gross value of over $\$ 550,000,000$ in 1974. The IVEP has two main purposes: (1) to document the present socioeconomic structure and environmental quality of the Imperial Valley prior to large-scale geothermal development; and (2) to conduct long-term studies resulting from the actual development of geothermal resources. The general goal of this work is to ensure that geothermal resource 
development in the Imperial Valley proceeds on an environmentally sound basis.

The IVEP is organized into six field research groups (air, water, ecosystem, subsidence and induced seismicity, human health, and socioeconomic) and an integrated assessment group with the responsibility for developing geothermal scenarios and assessing the impacts of these scenarios. Don Ermak described some of the air quality aspects of the project. Baseline air quality measurements are being made at six fixedlocation sampling stations. Each station has sensors to measure wind speed and direction, temperature, relative humidity, and the concentrations of several pollutants including $\mathrm{H}_{2} \mathrm{~S}, \mathrm{SO}_{2}, \mathrm{O}_{3}, \mathrm{CO}_{2}$, and $\mathrm{NH}_{3} \cdot \mathrm{A}$ mobile field laboratory is being used for source characterization of geothermal emissions. Predictions of the changes in air quality as a result of proposed geothermal development scenarios will be made using atmospheric transport models. These models include a climatological dispersion model, a three-dimensional particle in cell transport code, and a two-dimensional coupled transportkinetics code. In addition to comparing predicted pollutant levels with applicable standards, a major effort is concerned with estimating the impacts of geothermal emissions on agricultural productivity.

Los Alamos Scientific Laboratory is assessing the socioeconomic and environmental impact of energy resource develop- 
ment in the Rocky Mountains. This region has become a major focus of attention for energy development in recent years; nevertheless its traditionally low and stable population base, pristine air and water, and outstanding scenery complicate the social and environmental impacts associated with energy development. The LASL Regional studies Program is studying air, water, land, and economic and institutional impacts of energy development, and establishing a data base for the Rocky Mountain region. George Hinman, on sabbatical leave from Washington State University, and Ellen Leonard discussed the initial phases of their air quality efforts, which have been addressing the questions: What are the constraints on regional energy development that are imposed by air quality regulations? and, what are the damages caused by residual pollutants? To answer these questions LASL has adopted the "air basin" approach, applying a set of dispersion models made available from the Environmental Protection Agency called UNAMAP to these basins. Using the output from an energy supply model developed jointly by the stanford Research Institute and Gulf Oil Corporation they have estimated whether the emissions from hypothetical coal-fired power plants, coal gasification plants, and oil shale retort operations expected to be built in the Rocky Mountains during the rest of this century are consistent with existing state and federal air quality standards. In addition they are investigating the degree to which proposed amendments to the clean Air Act concerning 
prevention of significant air quality deterioration will restrict future energy development in this region. An additional major potential problem in resource development is the impact that any reduction in visibility due to anthropogenic emissions will have on the economic (i.e., tourist trade) and social fiber of the region. These types of impacts are difficult to assess on a regional scale using present methodologies, partly because of the complex problem of quantifying the changes in visibility to be expected, but even more because of people's reactions to changes in visibility. In addition the complex interactions of pollutant transport and diffusion in rough terrain are not very well factored into the assessments. Nevertheless, RSP efforts such as this begin to show the magnitude of air quality impacts of energy development. In addition they call out those areas which can benefit from further research by atmospheric scientists.

The scope of the Argonne National Laboratory RSP is to study the environmental impacts of coal utilization in the northern midwest states of Minnesota, Wisconsin, Illinois, Indiana, Ohio, and Michigan. Loren Habegger and Kenneth Brubaker described their approach of utilizing information from the energy supply and demand scenarios developed by the economists to examine two alternative siting strategies: one where the energy facilities are oriented toward the resource center, and the other where the facilities are oriented toward 
the load center. Their major effort is concentrated on the extraction and utilization of coal in Indiana and Illinois, although they are also considering the extraction of coal from the Williston basin in North Dakota. Two scales of modeling are used to assess air quality impacts. Over the short range they are applying a version of the Climatological Dispersion Model (CDM) developed by Busse and Zimmerman (1973), but modified so that dosages to populations from the various pollutants can be calculated. They have also added a straightforward linear transformation rate of $\mathrm{SO}_{2}$ to sulfate, and mixing height as part of the joint frequency distribution to the CDM. Over large travel distances a Langrangian statistical trajectory model developed by Bolin and Persson (1975) is being applied to the region using a one year data set to obtain regional annual average pollutant concentrations. From this information they will obtain average dosages to the population using $J$. S. Census Bureau data listing the number of people by latitude and longitude for 1970 .

The Regional Studies Program at Oak Ridge National Laboratory is studying coal utilization, and in particular the future development of coal-fired electric generating facilities, in the southeast United states. Brian Murphy demonstrated how air quality impacts are being evaluated using standard Gaussian plume models for short range assessments, and a regional transport and diffusion model developed 
by Heffter, et al (1975) for regional-scale assessments. The primary air pollution-related problems in this part of the country are not only the exposures to populations due to ambient concentrations, but also the impacts to ecosystems due to wet and dry deposition of airborne pollutants onto the terrestrial environment. Therefore in the models they apply in their assessments, they pay particular attention to the deposition process, looking at both the aerodynamic and surface component. The aerodynamic component is governed primarily by the surface roughness height and the wind speed in the boundary layer, but the surface component depends very much on the stomatal conditions within the leaves of the vegetation a diurnal and seasonal factor, and the leaf area index.

William Emanuel of ORNL then discussed the optimal energy facility siting program at oak Ridge, where information on power plant sizes, generating capacities, and emission rates is used to minimize impacts and maximize economic efficiency. He reiterated that little information is available on the effect of $\mathrm{SO}_{2}$ and sulfate deposition on ecosystems, and yet these impacts could have an effect on energy development in the southeast United states.

Ron Meyers of Brookhaven National Laboratory discussed the effort his group has undertaken to determine the impact that alternative energy strategies may have on the environment and health of the northeast United states. A major environmental 
problem in this part of the country is acid rain. He noted that much of the farmland is under the largest flux of pollutant transport. Health effects are an important component of their program, with a significant amount of effort directed toward epidemiological studies to relate the occurrences of disease such as lung cancer to air pollution. To do this Brookhaven is looking at pollutant transport in the immediate vicinity of power plants and over long distances, and is reconstructing the pollution of the last twenty years, comparing this to epidemiological records from hospitals so that pollution trends can be correlated with trends in lung cancer. Preliminary results indicate that large, tall stack fossil fuel power plants are the primary source of sulfates in the region. These sulfates are the result of ambient conversion of $\mathrm{SO}_{2}$, which is emitted from the stacks, over long distances of travel.

The trajectory modeling of Heffter, et al (1975) originally formed the basis for Brookhaven's regional transport model. Brookhaven's preliminary studies used deposition functions for both $\mathrm{SO}_{2}$ and sulfates, and a linear chemical transformation rate between $\mathrm{SO}_{2}$ and sulfate. Non-linear effects have been incorporated in more recent versions of the model. In addition they have included the precipitation data from 744 stations in the northeast to calculate pollutant washout. Both anthropogenic and biogenic sulfur sources are considered. The latter 
is determined by using estimated emission rates of $\mathrm{H}_{2} \mathrm{~S}$ from wetlands and linear transformation rates of $\mathrm{H}_{2} \mathrm{~S}$ to $\mathrm{SO}_{2}$ and sulfate. They are currently developing a mass-, momentum-, and energy-conservative flow field which incorporates the effects of topography and vertical temperature structure when reconstructing observed wind fields to force mass consistency . As with the other laboratories working on energy-related impact assessments, BNL has found terrain variations to have a significant effect on transport, dispersion, and deposition of pollutants.

\section{ASSESSMENT OBJECTIVES}

The workshop discussions became more philosophical when the question as to why we are even using models in the assessment program was raised. Loren Habegger first attempted to answer this by outlining the broad issues of air quality assessments: regulatory constraints, impacts on human health, and environmental impacts, including those on agricultural and managed forests, scenic, wilderness, and recreation areas, and natural ecology. In order to address these issues, scientists working in air quality assessments must be able to provide information at several levels, such as single facility impacts, clustered facility impacts, concentration of facilities in energy-rich areas'vs. dispersion of facilities, and regional impacts and inter-regional trade-offs. 
However, the point was raised that present regulatory constraints may appear unreasonable in the future as new data is collected, and they will change as a function of the type of impact. The BNL group is looking at historical pollution and epidemiological data to determine health effects, and they feel this is the area where the atmospheric scientist plays an important role in the assessment program. Obviously a close collaboration between meteorologists and epidemiologists is required.

However, the objective of the Regional Studies Program is to apply existing technology to assess energy-related impacts, and to identify those gaps in knowledge or methodologies which prevent proper or reasonable assessments to be made. Considerable controversy was generated among the workshop participants over whether these health effect studies constitute research or assessment activities. Some felt that research within an assessment program must continue before results are presented, while others felt that existing technology should be applied to actual problems (as long as the assessments are prefaced with error bands) so that future research and development work can be undertaken. In other words, air quality levels should be computed even when the health and ecological effects aren't known. Only in this way can future experimental efforts be guided. 
At the heart of these discussions, then, comes the recurring theme that atmospheric scientists must not only continue to work among themselves to improve the modeling techniques that are to be made available to assessment efforts, but also work with the other scientific disciplines such as epidemiologists, ecologists, biologists, sociologists and economists to guide the health and ecological effects research. Only in this way can appropriate information based on an integrated assessment be provided the decision maker. Thus, a goal coming out of this workshop discussion is to establish an inter-laboratory committee which will be set up to review and priortize knowledge gaps that are identified in the Regional Studies Program as well as in other related efforts as a means of guiding future research.

\section{ASSESSMENT TECHNIQUES}

A high level of communication is required between atmospheric scientists engaged in model development and scientists engaged in assessing "real world" problems. This feeling was expressed by Ching Ming Sheih of ANL and Larry Wendell of PNL, who provided the workshop with a modeler's view of the assessment effort.

Dr. Sheih saw his participation in the workshop as an opportunity to bring the modelers into the real world. He expressed three goals in this participation; 1) to exchange ideas with the assessment group and learn from them their 
spatial and temporal resolution requirements, 2) to discuss what is available to the modelers, and 3) to comment on those modeling techniques available. Numerous models have been developed for various situations that may be encountered in an assessment effort; for example, at ANL there is a lakebreeze model, a puff-grid pollutant dispersion model, an atomizer-scrubber model, a particulate coagulation and transport model, a regional scale statistical trajectory pollutant dispersion model (Bolin and Persson, 1975), and a puff-on-cell pollutant dispersion model (Eagon and Mahoney, 1972).

In commenting on modeling techniques that are available, Dr. Sheih noted that we began with the first generation Gaussian plume models, then went to second generation puff models. We are now working on third generation grid models, which attempt to solve the partial differential equations of diffusion. However, on the regional scale there is no third generation approach available, since there are eddy components smaller than grid size occurring in the atmosphere, changes in the inversion height requiring parameterization, and deposition velocities varying spatially and temporally by three orders of magnitude.

Dr. Sheih's discussion raised the issue on the availability of these models to the scientist working on assessment problems. Many of the participants recognized that even though the computer codes are available they still require a 
competent atmospheric scientist to run them. However, others feel that the codes should be made available to use by anyone, despite the inherent dangers in this. This issue was raised again and again throughout the workshop, emphasizing the need to have the model developer and model applicants collaborate closely to evaluate each other's needs and limitations.

Larry Wendell, who discussed the regional scale model development underway at PNL, expressed a word of caution on this issue. Model users want something now so they can make decisions now. However, the zeroth order assessment technologies have a tendency to acquire more and more credibility as they are passed up the chain of command to the decisionmaker. Recognizing this problem as scientists, there is a tendency to grab a new technology as it is developed and apply it to assessment problems. However, we need to be careful when doing this, and give consideration to the manner in which the decision-maker will use this new level of information when it is transferred to him.

The goal of the regional modeling development at PNL is to produce a tool for use in the MAP3S (Multi-state Atmospheric Power Production Pollution study) l/ program which will estimate $\mathrm{SO}_{2}$ and sulfate concentrations and deposition. Similar efforts are underway at $\mathrm{ANL}$ and $\mathrm{BNL}$, and three of the

I/This ERDA-sponsored project will assess experimentally and theoretically the fate of anthropogenic sulfur emissions in the northeast United States. Field efforts will be underway during the summer of 1976. 
participants at this workshop (Wendell, Sheih and Meyers) collaborated for a month during the summer of 1975 at Brookhaven to compare the various modeling techniques under development at each laboratory. Although at that time there was not enough upper air data available to obtain a statistical comparison of the three models, the investigators found both strong similarities and differences in the results. Larry Wendell noted that if a correlation exists between the trajectory and removal process (e.g., precipitation scavenging) or chemical conversion processes (as is the case for nonlinear reactions) then large differences may exist in the results between the statistical approach, such as the one used by $A N L$, and the "real time" wind and precipitation technique, such as being applied by PNL and BNL. Furthermore, Ron Meyers noted that the "smearing" and "filtering" of pollutant patterns using the statistical approach may not be adequate for much of the Regional Studies assessments, especially those correlating pollutant concentrations with health effects.

Bill Clements provided a brief description of the statistical treatment of diffusion being developed by clayton Watson and Sumner Barr at LASL, who have approached the problem using the Monte Carlo method. They divide atmospheric turbulence into three spectral regions, with the intermediate part consisting of the autocorrelation functions for turbulence that must be satisfied. He noted that traditionally we have 
parameterized turbulence in terms of a few quantities for diffusion estimation, but with this technique we are able to account more generally for turbulence structure and time and space variation in the mean transport wind.

\section{DATA NEEDS AND AVAILABILITY}

In the type of assessments such as those undertaken in the RSP, the availability of data and the type of data requirements becomes a critical concern. Brian Murphy and Ron Meyers led a discussion of the issue of data needs and availability by first describing what they each need and have in their program. Oak Ridge is in the process of obtaining a ten-year set of upper air data for use in their regional modeling. They have also found some good data sources through the Environmental Protection Agency with the SAROAD and NEDS systems. However, ORNL does not want to duplicate or reinvent a data base that has already been acquired elsewhere a reasonable goal considering the expenses involved in establishing data bases. In addition, they feel that, considering the tremendous volume of data becoming available, some method of abstracting averages of data is in order for the RSP.

Brookhaven, which is involved heavily not only in the RSP for the northeast United states but also the MAP3S program, has recently set up a data management team. They are presently acquiring meteorological data, including six-to- 
twelve hourly National weather Service observations and Northern Hemispheric Upper Air data, air quality and emission data, mortality and morbidity data, and data from the Federal Power Commission and Census Bureau. Since they feel smoothing data such as this may take out features that are desirable, BNL has not acquired the smoothed tapes.

Their air quality and emission data come primarily from NASN (National Atmospheric Surveillance Network) and NEDS (National Emission Data System) sources. However, they are able to supplement this with state data; noting, for example, that New York City air quality data comes second only to st. Louis for density. They have found, furthermore, that sulfate measurements appear to be much less reliable than sulfur dioxide measurements.

Other workshop participants identified additional data sources of value to the RSP. These include data collected in the preparation of Air Quality Maintenance Plans, and in Environmental Impact Statements, land use data from the ERTS satellite, detailed topographic data from the National Cartographic Information Center, and data from SEAS (Strategic Environmental Assessment System) developed by the Environmental Protection Agency. Nevertheless, use of all this data, particularly on an interlaboratory exchange basis, is constrained at the computer center by the number of discs available and the speed at which tapes can be mounted. 
An additional aspect of the RSP has been establishment of the Interlaboratory Working Group for Data Exchange (IWGDE). The IWGDE is working to develop standards and points of contact for the exchange of data between ERDA laboratories. Common systems for managing data at the various laboratories should enhance the communication process. SYSTEM 2000 is available at some laboratories and is expected to be installed at or made available to the other locations. PROGENITOR was mentioned as a generator for programs to manage data which is hardware independent. It is implemented in COBOL. A survey of data bases and models has been conducted and results are available from Viktor Hampel at LLL. This work has alphabetized significant words from titles to provide easy access to abstracts of the data bases and models. The work of the IWGDE will improve interlaboratory communication and exchange of data and thereby reduce efforts which duplicate another's accomplishments.

\section{SUMMARY}

The workshop provided a unique opportunity for scientists of varying technical backgrounds working on regional air quality and meteorological assessments to exchange ideas and information, and to interact with scientists involved in developing the type of assessment models being applied in the Regional Studies Program. A number of important conclusions can be drawn from the discussions that were held during the workshop. 
First, all of the laboratories have incorporated regional transport into their programs to one degree or another, and are concerned not only with regulatory constraints but also health and ecological effects in their assessments. It has been observed that in most cases regional air quality levels are in the "in between" zone: below existing state and federal air quality standards, but above the level that could be considered safe from long term health and ecological concern. The notable exception is in the northeastern United States, where present standards are regularly exceeded in urban and industrial areas. Since the imposition of sulfate standards may be imminent, there is considerable concern that safe levels of this pollutant may be exceeded on a large scale. In addition, legislation for the prevention of significant air quality deterioration may have an important impact on future energy facility siting, particularly in the western United states, and will require regional modeling in the siting studies.

Second, there are clear regional differences among the approaches. In the West, LASL is putting more emphasis on local impacts and the "carrying capacity" of the atmosphere in various energy resource regions, while PNL is concentrating on regional impacts and their implication on agricultural production. Lawrence Livermore is looking more specifically at geothermal power potential and the impacts of that develop- 
ment on agriculture. In the East where population densities are much greater than the west and agricultural production less the effort is oriented more toward health effects, and more emphasis is placed on regional transport and deposition of $\mathrm{SO}_{2}$ and sulfates both at $\mathrm{ANL}$ and $\mathrm{BNL}$. However, agricultural production and ecological effects are not being ignored by any of the laboratories, and particular emphasis is placed on ecological studies by ORNL.

Third, the effects of topography on local and regional transport have been identified as very important, particularly in the energy-rich regions of the west, and are given special consideration by all laboratories. In addition, the methods by which pollutants deposit onto various surfaces under different environmental conditions is given extensive study.

Fourth, the RSP provides a unique opportunity for atmospheric scientists to work together with scientists of other disciplines, particularly epidemiologists, ecologists, biologists, sociologists and economists, to provide information to the decision maker on energy-related environmental impacts. This activity also requires the atmospheric scientist to collaborate closely with the model developer so that the needs of each are factored into both the research and assessment programs.

Fifth, the atmospheric scientist must work with multidisciplinary data bases, recognizing what is important not 
only in the immediate realms of his profession but also from other, sometimes unrelated professions, for use in the assessment programs. These data bases, as well as the interlaboratory cooperation required for their acquisition by all laboratories without needless duplication of effort and waste of research money, are being developed out of the Regional Studies Program.

our nation is dedicated to the goal of energy independence by the $1980^{\prime} \mathrm{s}$. However, it is important that the attainment of this goal does not conflict with or detract from the health and welfare of its people, the production of its food, the diversity of its ecosystems, and the quality of life and beauty of the landscape. The atmospheric scientist, through assessment efforts such as the Regional studies Program, must recognize the important role he plays in society to achieve these goals.

\section{ACKNOWLEDGMENTS}

Although responsibility for many of the views expressed in this report rest with the author, the hard work and imaginative thinking of all workshop participants contributed to this discussion.

This work was supported by Contract E(45-1)-1830 from the Energy Research and Development Administration. 


\section{REFERENCES}

Busse, Adrian D. and John R. Zimmerman, 1973: User's Guide for the Climatological Dispersion Model, EPA-R4-73-024, National Environmental Research Center, Office of Research and Development, U. S. Environmental Protection Agency, Research Triangle Park, NC, 27711.

Bolin, Bert and Christen Persson, 1975: Regional Dispersion and Deposition of Atmospheric Pollutants with Particular Application to Sulfur Pollution Over Western Europe, Tellus XXVII (3):281-310.

Heffter, Jerome L., Albin D. Taylor and Gilbert J. Ferber, 1975: A Regional-Continental Scale Transport, Diffusion, and Deposition Model, NOAA Technical Memorandum ERI ARL-50, Air Resources Laboratories, Silver Spring, MD, June 1975.

Eagan, B. A. and J. R. Mahoney, 1972: Numerical Modeling of Advection and Diffusion of Urban Area-Source Pollutants, J. Appl. Meteor. 11, 312-322. 


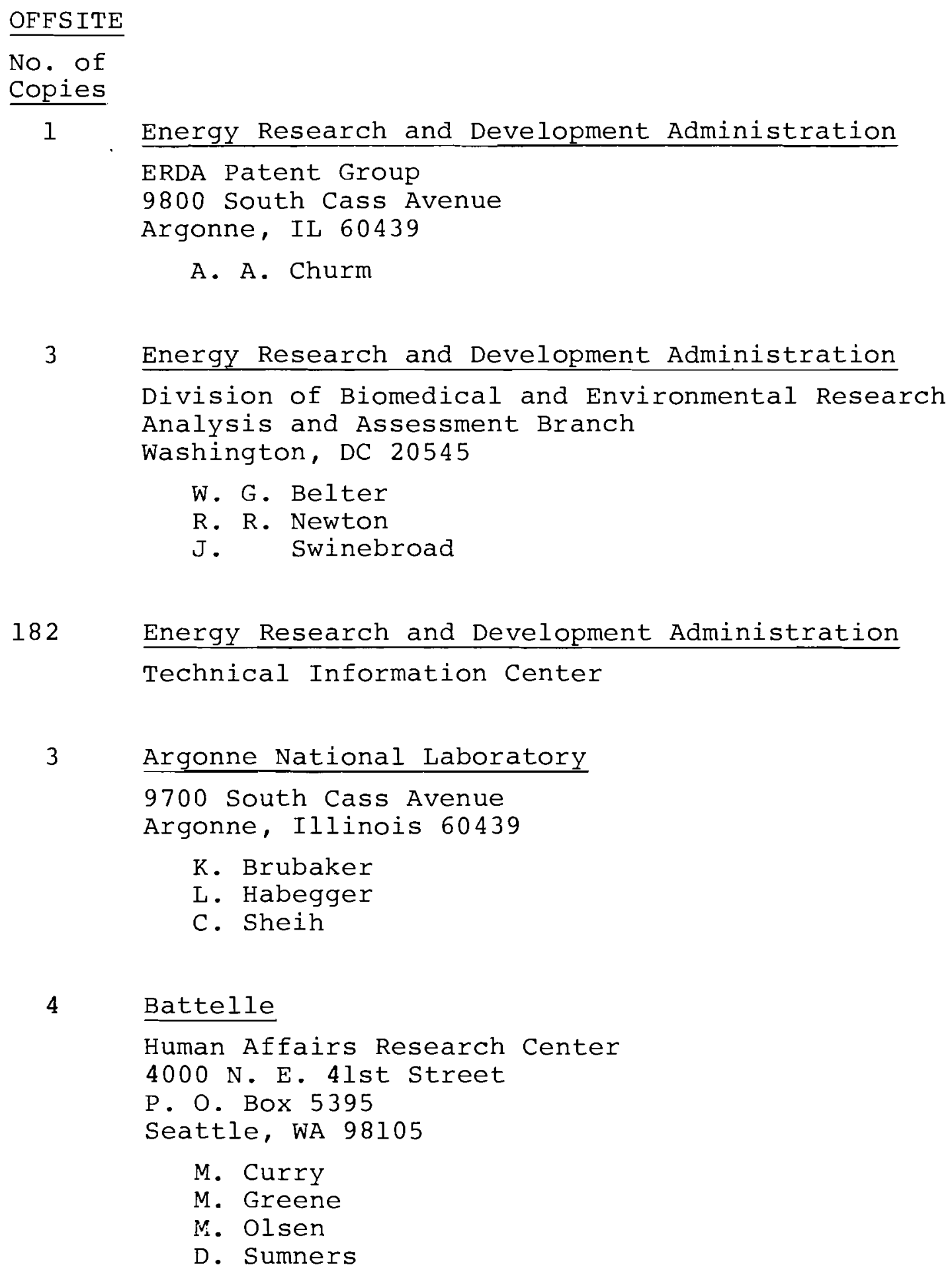

182 Energy Research and Development Administration

Technical Information Center

3 Argonne National Laboratory

9700 South Cass Avenue

Argonne, Illinois 60439
K. Brubaker
L. Habegger
C. Sheih

4

Battelle

Human Affairs Research Center

4000 N. E. 4lst Street

P. O. Box 5395

Seattle, WA 98105

M. Curry

M. Greene

M. Olsen

D. Sumners 


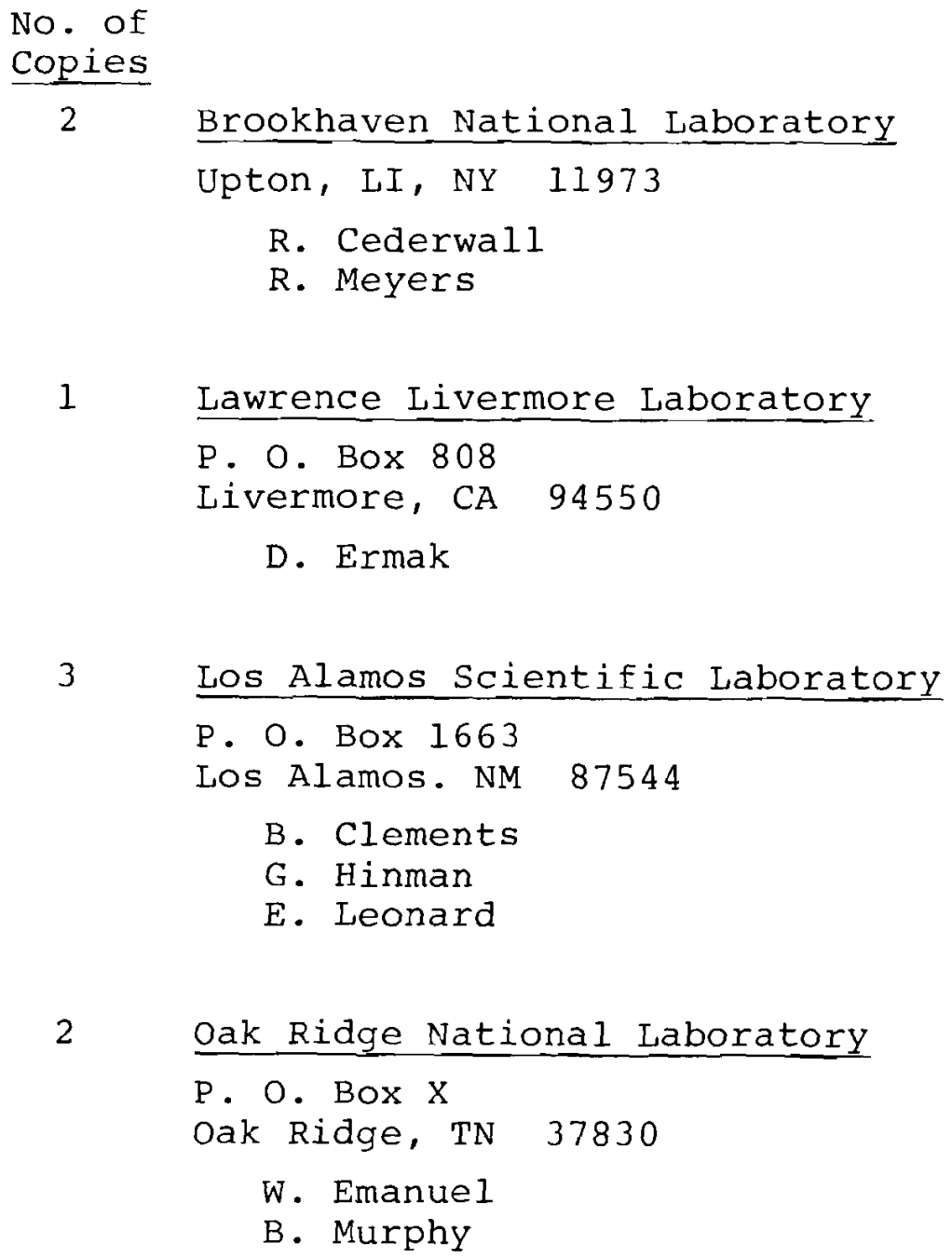

2 Oak Ridge National Laboratory

P. O. Box X

Oak Ridge, TN 37830

W. Emanuel

B. Murphy

\section{ONSITE}

No. of Copies

Energy Research and Development Administration

Richland Operations office

Richland, WA 99352

P.F.X. Dunigan, Jr.

P. G. Holsted

B. J. Melton

M. W. Tiernan

J. A. Zillich 
No. of

Copies

47

Battelle-Northwest

J. W. Currie

W. E. Davis

R. L. Drake

J. G. Droppo

C. E. Elderkin

D. E. Elliott

L. E. Erickson

J. C. Fox

D. W. Fraley

E. R. Hill

J. J. Jacobson

D. C. Powell

D. S. Renne (15)

R. H. Sauer

S. J. Shupe

C. L. Simpson

W. H. Swift (10)

L. I. Wendell

G. L. Wilfert

Technical Information (3)

Technical Publications (2) 